\title{
ARMAZENAMENTO DE SEMENTES DE SOJA DESSECADAS E AVALIAÇÃO DA QUALIDADE FISIOLÓGICA, BIOQUÍMICA E SANITÁRIA ${ }^{1}$
}

\author{
*ANDRÉ LUIZ DE SOUZA LACERDA²; EDSON LAZARINI³; MARCO EUSTÁQUIO DE SÁ3; WALTER VERIANO VALÉRIO FILHO4
}

\begin{abstract}
RESUMO - O trabalho teve o objetivo de avaliar as características fisiológicas, bioquímicas e sanitárias das sementes de soja colhidas após dessecação com quatro dessecantes, em diferentes épocas, armazenadas por seis meses e tratadas com um fungicida. O experimento foi realizado no Laboratório de Sementes da UNESP - Campus de Ilha Solteira. As plantas de soja do cultivar IAC-15 foram dessecadas, no ano agrícola 1997/98, com: paraquat, diquat, mistura paraquat + diquat e glufosinato de amônio, nas dosagens de 400, 300, 200+150 e 400 g.i.a./ha aplicados a partir do estádio $\mathrm{R}_{6}$ até $\mathrm{R}_{7}$, com intervalos de 5 dias. As sementes foram colhidas e acondicionadas em câmara seca, com umidade relativa em torno de $40 \%$ e temperatura entre 17 e $20^{\circ} \mathrm{C}$, por um período de seis meses. As análises foram realizadas com sementes tratadas com o fungicida thiabendazole (20 g.i.a./100 kg de sementes) e sementes não tratadas. Após análise e interpretação dos resultados obtidos, pode-se concluir que as sementes não apresentaram qualidades fisiológicas suficientes para comercialização. O tratamento com o dessecante glufosinato de amônio apresentou significativamente, menores valores de germinação. O teor de proteína não foi afetado pela dessecação, entretanto, para o extrato etéreo houve redução deste componente nas sementes dessecadas. O produto paraquat aplicado nas primeiras épocas resultou maior incidência de Fusarium spp., enquanto que, para o Phomopsis spp., menor incidência independente das épocas de aplicações.
\end{abstract}

Termos para indexação: soja, armazenamento, germinação, vigor, sanidade.

\section{STORAGE OF DESSICATED SOYBEAN SEED AND THE EVALUATION OF PHYSIOLOGIC, BIOCHEMICAL AND SANITARY CHARACTERISTICS}

\begin{abstract}
The objective of the study was the evaluation of the physiologic, biochemical and sanitary characteristics of soybeans seeds after dessication with four dessicants, in different times, stored for six months and treated with fungicide. The experiment was carried out, in the Seed Laboratory, at UNESP - Ilha Solteira. The soybean plants of the cultivar IAC-15 were desiccated, in the agricultural year 1997/98, with: paraquat, diquat, paraquat + diquat (mixed in tank) and ammonium glufosinate at rates of 400, 300, 200+150 and 400 g.i.a. ha-1 . starting in the $\mathrm{R}_{6}$ stage till $\mathrm{R}_{7}$, at five-day intervals. The seeds were harvested and placed in a dry chamber with relative humidity around $40 \%$ and temperature between 17 and $20^{\circ} \mathrm{C}$ for six months. The analyses were carried out with non treated seeds and seeds treated with thefungicide thiabendazole (20 g.i.a/100 $\mathrm{kg}$ of seeds). The conclusions were: the seeds did not present enough physiologic qualities for commercialization, and the dessicant ammonium glufosinate presented, significantly, smaller germination values. The protein content was not affected by the dessication, however, for the
\end{abstract}

\footnotetext{
${ }^{1}$ Aceito para publicação em 12/12/2003; parte da dissertação de mestrado do primeiro autor. Curso de pós-graduação em Agronomia, área de concentração em Sistemas de Produção - Faculdade de Engenharia/UNESP - Campus de Ilha Solteira.

${ }^{2}$ Eng $^{\circ}$ Agr $^{\circ}$, MSc, Doutor em Fitotecnia; Rua Padre Francisco de Abreu Sampaio, 269, 13030-350, Campinas, SP; e-mail: alslacer@esalq.usp.br

${ }^{3}$ Profs., Drs., Departamento de Fitotecnia, Economia e Sociologia Rural -
}

FEIS/UNESP; Av. Brasil, 56, 15385-000, Ilha Solteira, SP; e-mail: lazarini@agr.feis.unesp.br; mesa@agr.feis.unesp.br

${ }^{4}$ Prof., Dr., Departamento de Matemática - FEIS/UNESP; Av. Brasil, 56, 15385-000, Ilha Solteira, SP; e-mail: wvvf@fqm.feis.unesp.br

* Os autores agradecem o apoio financeiro da FAPESP e aos revisores anônimos pelas suas sugestões para o enriquecimento do artigo científico. 
ethereal extract there was reduction in this component in thes dessicated seeds. The product paraquat applied in the first times resulted in larger incidence of Fusarium spp. in the soybean seeds, while, for the Phomopsis spp. smaller indifferent incidence of the times of applications.

Index terms: soybean, storage, germination, vigour, healthy.

\section{INTRODUÇÃO}

O grau de umidade das sementes e a temperatura de armazenamento são dois fatores de maior influência sobre a manutenção de sua viabilidade (Ward \& Powell, 1983). A maioria das espécies cultivadas possui características ortodoxas, na qual, um aumento do conteúdo de água das sementes ou da umidade relativa do ambiente, ou ainda, da temperatura de armazenamento, resulta em uma rápida perda da viabilidade (Roberts, 1973), reduzindo a porcentagem de emergência a campo, além de diminuir o potencial de armazenamento (Matthews, 1981).

Silva (1989) cita que o potencial de conservação de sementes de soja depende diretamente da qualidade fisiológica das mesmas no início do período de armazenamento e está intimamente relacionada ao momento de colheita.

O ponto considerado de colheita da soja é o estádio reprodutivo R8, porém, antes desta fase, a soja atinge sua maturação fisiológica no estádio reprodutivo R7. Nesta fase as sementes apresentam máximo vigor e germinação, entretanto, o teor de umidade das sementes é aproximadamente de 50 a $60 \%$ o que torna inviável a operação de colheita das sementes, devido aos danos físicos nas sementes e à grande quantidade de folhas que impossibilitam a colheita mecânica.

Para contornar esses problemas a utilização da dessecação química é a uma das formas encontradas por alguns produtores de sementes. Esses produtos químicos têm por características desidratar as sementes e promover antecipação da colheita de soja sem alterar a produção por um período máximo de sete dias (Lacerda et al., 2001), evitando com isso, que as mesmas fiquem à mercê das condições ambientais como oscilações de temperatura e umidade que são responsáveis pela queda do potencial fisiológico das sementes.

Gomes (1982) utilizando o paraquat e mistura de paraquat + diquat, e Pastore et al. (1985) utilizando paraquat na dessecação de soja, obtiveram sementes de melhor qualidade, se comparada com as que não sofreram dessecação.

Outras características importantes a serem investigadas pela aplicação de dessecantes são as propriedades bioquímicas das sementes, ou seja, os teores de proteínas e óleo. Dependendo do dessecante, da fase em que são aplicados e da época de colheita das sementes, estes fatores, podem influen- ciar nos teores destes componentes nas sementes. Soares (1995) estudando o efeito do paraquat, verificou que este não afetou o teor da fração lipídica dos grãos de soja. Também Wilcox et al. (1972) concluíram que o retardamento da colheita não afetou o teor de proteína, porém notaram um aumento de 5\%, em média, no teor de óleo. Entretanto, Durigan et al. (1989) disseram que o retardamento de colheita afeta os teores de proteína e óleo.

O potencial ou qualidade fisiológica das sementes depende também da incidência de fungos. Estudos realizados por Henning (1987) demonstraram que Phomopsis spp. perde a viabilidade do fungo durante a armazenagem em condições ambiente, ocorrendo, ao mesmo tempo, aumento gradual na porcentagem de germinação em laboratório.

O presente trabalho teve o objetivo de avaliar as características fisiológicas, bioquímicas e sanitárias das sementes de soja colhidas após dessecação com quatro dessecantes, em diferentes épocas, armazenadas por seis meses e tratadas com um fungicida.

\section{MATERIAL E MÉTODOS}

O ensaio foi instalado na área experimental da Fazenda de Ensino e Pesquisa (FEP) pertencente a Faculdade de Engenharia de Ilha Solteira - UNESP, localizada no município de Selvíria - MS, apresentando como coordenadas geográficas $51^{\circ} 22^{\prime} \mathrm{W}$ e $20^{\circ} 22^{\prime} \mathrm{S}$ e aproximadamente $335 \mathrm{~m}$ de altitude, $1.370 \mathrm{~mm}$ de precipitação e $23,5^{\circ} \mathrm{C}$ de temperatura média anual.

O delineamento experimental utilizado foi em blocos casualizados em esquema fatorial $4 \times 4$ (produtos dessecantes e épocas de aplicação) com 4 repetições. Os dessecantes utilizados foram paraquat, diquat, paraquat + diaquat (mistura em tanque) e glufosinato de amônio nas dosagens de 400, 300, 200+150 e 400 g.i.a./ha, respectivamente. Foi considerada como testemunha a parcela que não foi feita dessecação. As aplicações foram realizadas a partir do estádio $\mathrm{R}_{6}$ até $\mathrm{R}_{7}$, com intervalos de 5 dias. A identificação dos estádios reprodutivos baseou-se em Fehr et al. (1971).

As parcelas dessecadas com paraquat, diquat, paraquat + diquat e glufosinato de amônio em 05/03, 10/03 e 15/03 tiveram suas sementes colhidas no dia 27/03/98 (colheita de 
verão); e as dessecadas em 20/03, as sementes foram colhidas em 03/04/98 (colheita de verão), juntamente com a testemunha. Ocorreu então, antecipação da colheita em 7 dias, pela diferença de ciclo da cultura da testemunha e as aplicações realizadas nas três primeiras épocas. O critério utilizado para colheita foi o monitoramento da umidade das sementes (13 a 15\% base úmida), determinada em laboratório. Foram feitas quatro amostragens por tratamento fatorial (dessecantes e época de aplicação) para realização do teste de germinação padrão e teores de proteína e extrato etéreo (bioquímico). Feito isso, as sementes foram acondicionadas em câmara seca, umidade relativa em torno de $40 \%$, e temperatura entre 17 e $20^{\circ} \mathrm{C}$, por um período de seis meses, e avaliadas novamente a qualidade fisiológica e sanitária na época considerada de comercialização (setembro/outubro), pela amostragem de quatro repetições por tratamento. O teste de germinação foi realizado em sementes tratadas, momento antes a realização do teste, com thiabendazole (20 g.i.a./100 kg de sementes) e em sementes não tratadas. As demais avaliações de qualidade fisiológica e a inspeção da qualidade sanitária foram efetuadas em sementes que não receberam tratamento de fungicida.

Os testes utilizados para essas avaliações foram:

Teste de germinação padrão: realizado com 4 subamostras de 50 sementes para cada tratamento, distribuídas em rolos de papel toalha e colocadas para germinar a $25^{\circ} \mathrm{C}$. As avaliações de germinação foram efetuadas aos 5 e 8 dias, após a instalação do teste, segundo as recomendações contidas nas Regras para Análise de Sementes (Brasil, 1992).

Envelhecimento acelerado: realizado com 4 sub-amostras de 50 sementes para cada tratamento. As sementes foram distribuídas sobre telas de alumínio, fixadas no interior de caixas plásticas adaptadas, funcionando como compartimentos individuais (mini-câmaras) onde foram colocados $40 \mathrm{ml}$ de água. As caixas foram tampadas e mantidas em câmara de envelhecimento, regulada a $42^{\circ} \mathrm{C}\left( \pm 0,3^{\circ} \mathrm{C}\right)$, onde permaneceram por 48 horas (AOSA, 1983). Após este período, as sementes foram colocadas para germinar a $25^{\circ} \mathrm{C}$; a contagem do número de plântulas normais foi realizada após 5 dias da instalação do teste.

Condutividade elétrica: em cada tratamento utilizouse 4 amostra de 25 sementes. As amostras foram pesadas em uma balança de precisão, colocadas para embeber em um recipiente (copo plástico) contendo $75 \mathrm{ml}$ de água destilada e, então, mantidas em câmara (germinador) à temperatura de $25^{\circ} \mathrm{C}$, durante 24 horas. Após este período, fez-se a leitura da condutividade elétrica na solução de embebição, utilizando- se um condutivímetro digital, cujos resultados foram expressos em $\mu \mathrm{mhos} / \mathrm{cm} / \mathrm{g}$.

Teores de proteína: o valor da \% da proteína foi obtido pela multiplicação do valor do $\mathrm{N}$ total, obtido pelo método microkjeldahl, pelo fator 6,25 conforme descrito por Malavolta et al. (1989).

Extrato etéreo: o extrato etéreo contido nas sementes foi determinado por extração com solvente orgânico (hexano) a quente por oito horas utilizando-se de extrator soxhlet, segundo metodologia descrita por Silva (1981).

Incidência de patógenos: amostras de 50 sementes de cada parcela foram acondicionadas em caixa plástica (tipo gerbox), contendo papel de filtro ("blotter”) previamente umedecido com água destilada e esterilizada. As sementes passaram por tratamento de embebição de água por 24 horas e de resfriamento a $-20^{\circ} \mathrm{C}$ (freezer) por 24 horas, sendo posteriormente levadas ao germinador com temperatura em torno de $25^{\circ} \mathrm{C}$, permanecendo por mais 7 dias. Na seqüência, realizou-se a identificação dos patógenos que se manifestaram através do desenvolvimento de hifas e estruturas reprodutivas, peculiares a cada espécie.

Foi realizada a análise de variância dos dados, através do Teste F. As análises estatísticas foram realizadas com o auxílio do programa SAS, sendo a comparação entre médias, efetuada pelo teste de Tukey ao nível de 5\% de probabilidade. A porcentagem de infecção de sementes por fungos foram transformados em Raiz Quadrada (Variável+1) e, nos casos onde a interação épocas de aplicação x dessecantes foi significativa, realizou-se o desdobramento dos graus de liberdade para verificar os efeitos de época dentro de dessecantes e de dessecante dentro de épocas.

\section{RESULTADOS E DISCUSSÃO}

\section{Germinação e vigor das sementes}

Na Tabela 1, estão os resultados dos dados obtidos dos testes de qualidade fisiológica e as análises estatística preliminares das sementes colhidas em março/abril (safra de verão) e armazenadas por seis meses (setembro/outubro) próximo a época de comercialização. Verificou-se que as sementes não obtiveram índices de emergência suficientes para comercialização. A porcentagem de germinação de sementes armazenadas e tratadas com fungicidas foram inferiores aos das sementes não tratadas, podendo o fungicida utilizado, ter influenciado negativamente em fases do processo de germinação, mesmo sendo este recomendado no tratamento de sementes de soja. Houve efeito de épocas apenas nas sementes 
TABELA 1. Valores médios de germinação de sementes não tratadas (colhidas na safra de verão); de germinação de sementes armazenadas por seis meses tratadas e não tratadas; emergência a campo, envelhecimento acelerado e condutividade elétrica em sementes armazenadas por seis meses e não tratadas em função da aplicação de dessecantes em diferentes épocas ${ }^{1}$.

\begin{tabular}{|c|c|c|c|c|c|c|}
\hline \multirow[t]{2}{*}{ Épocas/dessecantes } & \multirow{2}{*}{$\begin{array}{l}\text { Germinação } \\
\text { colheita de } \\
\text { verão } \\
(\%)\end{array}$} & \multicolumn{2}{|c|}{$\begin{array}{c}\text { Germinação } \\
\text { armazenadas } \\
(\%)\end{array}$} & \multirow{2}{*}{$\begin{array}{c}\text { Emergência } \\
\text { no campo } \\
\text { armazenadas } \\
(\%)\end{array}$} & \multirow{2}{*}{$\begin{array}{c}\text { Envelhecimento } \\
\text { acelerado } \\
\text { armazenadas } \\
(\%) \\
\end{array}$} & \multirow{2}{*}{$\begin{array}{c}\begin{array}{c}\text { Condutividade } \\
\text { elétrica }\end{array} \\
\text { armazenadas } \\
(\mu \mathrm{mhos} / \mathrm{cm} / \mathrm{g}) \\
\end{array}$} \\
\hline & & Tratadas $^{2}$ & Não tratadas & & & \\
\hline Fatorial & 62 & 60 & 71 & 66 & $65 \mathrm{~b}$ & 104 \\
\hline Testemunha & 68 & 51 & 66 & 63 & $79 a$ & 101 \\
\hline 05/03 & 66 & 63 & $69 a b$ & 63 & $54 \mathrm{~b}$ & $113 \mathrm{a}$ \\
\hline $10 / 03$ & 66 & 59 & $76 a$ & 63 & $55 \mathrm{~b}$ & $106 a b$ \\
\hline $15 / 03$ & 71 & 60 & $75 a b$ & 69 & $68 a$ & $94 \mathrm{~b}$ \\
\hline $20 / 03$ & 71 & 61 & $66 \mathrm{~b}$ & 69 & $78 \mathrm{a}$ & $103 \mathrm{~b}$ \\
\hline Paraquat & 75 & $64 a$ & $76 a$ & 65 & $59 \mathrm{~b}$ & $104 a b$ \\
\hline Diquat & 71 & $67 \mathrm{a}$ & $76 a$ & 69 & $74 a$ & $101 \mathrm{~b}$ \\
\hline Paraquat+diquat & 68 & $67 \mathrm{a}$ & $71 \mathrm{a}$ & 70 & $64 a$ & $99 \mathrm{~b}$ \\
\hline Glufosinato de amônio & 61 & $46 \mathrm{~b}$ & $61 \mathrm{~b}$ & 61 & $59 \mathrm{~b}$ & $113 a$ \\
\hline \multicolumn{7}{|l|}{ Teste F } \\
\hline Fatorial vs Testemunha & $0,00^{\mathrm{ns}}$ & $3,43^{\mathrm{ns}}$ & $1,05^{\mathrm{ns}}$ & $0,33^{\mathrm{ns}}$ & $4,34^{*}$ & $0,31^{\mathrm{ns}}$ \\
\hline Épocas (E) & $0,47^{\mathrm{ns}}$ & $0,52^{\mathrm{ns}}$ & $3,20^{*}$ & $1,57^{\mathrm{ns}}$ & $11,66^{* *}$ & $9,05^{* *}$ \\
\hline Dessecantes (D) & $2,31^{\mathrm{ns}}$ & $16,07 * *$ & $5,94 * *$ & $2,66^{\mathrm{ns}}$ & $4,30 * *$ & $5,25 * *$ \\
\hline $\begin{array}{l}\text { E. * D. } \\
\text { DMS Tukey (5\%) }\end{array}$ & $1,33^{\mathrm{ns}}$ & $5,76^{* *}$ & $2,00^{\mathrm{ns}}$ & $2,50 *$ & $4,27^{* *}$ & $1,98^{\mathrm{ns}}$ \\
\hline Épocas e Dessecantes & 14,9 & 9,6 & 10,7 & 9,4 & 12,8 & 10,2 \\
\hline CV (\%) & 23,3 & 17,0 & 16,0 & 15,3 & 21,1 & 10,5 \\
\hline
\end{tabular}

${ }^{1}$ Médias seguidas da mesma letra não diferem entre si pelo Teste de Tukey ao nível de 5\% de probabilidade.

${ }^{2}$ Sementes tratadas com fungicida thiabendazole (20 g.i.a./100 kg de sementes).

armazenadas não tratadas e a aplicação realizada no dia 20/03, proporcionou menor índice de germinação diferindo significativamente da realizada em 10/03, sendo esta não diferente significativamente a efetuada no dia 15/03.

Quanto ao efeito dos dessecantes ocorreram menores valores de germinação nas sementes de plantas dessecadas com o glufosinato de amônio, diferenciando significativamente dos demais produtos químicos dessecantes. Esse comportamento também foi observado no teste de germinação realizado nas sementes colhidas na safra de verão, evidenciando que as condições de armazenamento não influenciaram nesta característica da semente.

Os valores observados de emergência a campo na Tabela 1, estão bastante coerentes com os de envelhecimento acelerado e condutividade elétrica. De acordo com Marcos Filho et al. (1987), o objetivo básico de se analisar o vigor das sementes é identificar possíveis diferenças na qualidade fisio- lógica de lotes que apresentem poder germinativo semelhante, pois, freqüentemente, observam-se lotes de sementes que apresentam germinação semelhante, exibindo comportamento distintos no campo e ou no armazenamento.

O efeito da interação significativa de épocas e dessecantes na germinação padrão em laboratório em sementes de soja armazenadas e tratadas com fungicidas, foram inseridos na Tabela 2. Verificou-se que somente o paraquat aplicado em 10/03 proporcionou valores suficiente para comercialização de sementes, ou seja, acima de $80 \%$ de germinação. O glufosinato de amônio foi o tratamento menos recomendado na dessecação de lavoura de soja com a finalidade de produção de sementes, pois ocasionou os menores valores de porcentagem de germinação, sendo significativo nas duas primeiras épocas (05/03 e 10/03), porém ocorreu aume nto quando aplicado a partir da terceira época (15/03). 
Na Tabela 3, encontra-se a interação significativa para variável emergência a campo em sementes de soja armazenadas e não tratadas com fungicidas. O comportamento das sementes semeadas no campo foram muito semelhantes aos realizados em laboratório (papel Germitest) (Tabela 2), e de maneira geral, foram melhores, principalmente para o glufosinato de amônio. Deve-se ressaltar que, talvez, as condições de realização do teste de emergência a campo foram totalmente favoráveis à emergência. Tais fatores como menor oscilação de temperatura, maior disponibilidade hídrica, condições desfavoráveis ao desenvolvimento de agentes fitopatogênicos e entre outros, poderiam ter ocasionado melhores condições de germinação e emergência das sementes.

O teste de vigor observado na Tabela 4, mostrou que as sementes provenientes das duas primeiras aplicações (05/03 e 10/03) proporcionaram menores valores de germinação quando essas foram envelhecidas. Talvez pelo fato de que, nessas épocas, quando foram efetuadas as aplicações, as sementes ainda não teriam atingido sua maturidade fisiológica e seriam mais sensíveis ao processo de envelhecimento. Quanto ao efeito dos dessecantes, observa-se que o paraquat e diquat proporcionaram sementes de maior vigor, sendo de 86 e 88\%, respectivamente, quando aplicados em estádio fenológico da cultura de soja próximo ao $\mathrm{R}_{7}$.

Os dados de condutividade elétrica (Tabela 1) indicaram que, à medida que avançaram as épocas de aplicações, houve queda nos valores dos mesmos, o que permite dizer que ocorreu melhor formação e organização das paredes celulares (maturação fisiológica), pois o sistema de membranas celulares é a última estrutura a organizar-se antes da maturidade fisiológica e a primeira a exibir as alterações degenerativas que caracterizam a deterioração das sementes. A falta de integridade das membranas pode acarretar a lixiviação de açúcares, aminoácidos, eletrólitos e outras substâncias solúveis em água (Heydecker, 1974).

Marcos Filho et al. (1982), trabalhando com soja, observaram que a permeabilidade das membranas celulares durante a maturação das sementes apresentou correlação altamente significativa com os dados de lixiviação de potássio e correlação negativa com os testes de germinação, primeira contagem do teste de germinação e envelhecimento acelerado. Constataram ainda que, sementes colhidas em épocas subsequentes à
TABELA 2. Desdobramento da interação épocas $x$ dessecantes para o teste de germinação em laboratório em sementes tratadas e armazenadas por seis meses ${ }^{1}$.

\begin{tabular}{|c|c|c|c|c|}
\hline \multirow{2}{*}{ Dessecantes } & \multicolumn{4}{|c|}{ Épocas de aplicação } \\
\hline & $05 / 03$ & $10 / 03$ & $15 / 03$ & $20 / 03$ \\
\hline Paraquat & $64 \mathrm{ABb}$ & 83Аа & $56 b$ & $52 \mathrm{Bb}$ \\
\hline Diquat & $72 \mathrm{~A}$ & $56 \mathrm{~B}$ & 67 & $72 \mathrm{~A}$ \\
\hline Paraquat+diquat & $67 \mathrm{AB}$ & $72 \mathrm{AB}$ & 62 & $67 \mathrm{AB}$ \\
\hline Glufosinato de amônio & $50 \mathrm{Ba}$ & $\mathrm{Cb}$ & $55 a$ & $54 \mathrm{Ab} \mathrm{a}$ \\
\hline
\end{tabular}

DMS: Época dentro de dessecantes $=19$

Dessecante dentro de épocas $=19$

${ }^{1}$ Médias seguidas pela mesma letra, minúscula na linha e maiúscula na coluna, não diferem entre si pelo teste de Tukey, ao nível de 5\% de probabilidade.

TABELA 3. Desdobramento da interação época $x$ dessecantes para o teste de emergência a campo em sementes não tratadas e armazenadas por seis meses ${ }^{1}$.

\begin{tabular}{lllll}
\hline \multirow{2}{*}{\multicolumn{1}{c}{ Dessecantes }} & \multicolumn{4}{c}{ Épocas de aplicação } \\
\cline { 2 - 5 } & $\mathbf{0 5 / 0 3}$ & $\mathbf{1 0 / 0 3}$ & $\mathbf{1 5 / 0 3}$ & $\mathbf{2 0 / 0 3}$ \\
\hline Paraquat & $54 \mathrm{~b}$ & $75 \mathrm{Aa}$ & $64 \mathrm{ab}$ & $67 \mathrm{ab}$ \\
Diquat & $70 \mathrm{ab}$ & $56 \mathrm{BCb}$ & $76 \mathrm{a}$ & $73 \mathrm{ab}$ \\
Paraquat+diquat & 70 & $74 \mathrm{AB}$ & 69 & 68 \\
Glufosinato de amônio & $60 \mathrm{ab}$ & $50 \quad \mathrm{Cb}$ & $65 \mathrm{ab}$ & $69 \mathrm{a}$ \\
\hline
\end{tabular}

DMS: Época dentro de dessecantes $=19$

Dessecante dentro de épocas $=19$

${ }^{1}$ Médias seguidas pela mesma letra, minúscula na linha e maiúscula na coluna, não diferem entre si pelo teste de Tukey, ao nível de 5\% de probabilidade.

TABELA 4. Desdobramento da interação épocas $x$ dessecantes para o teste envelhecimento acelerado em sementes não tratadas e armazenadas por seis meses ${ }^{1}$.

\begin{tabular}{lllll}
\hline \multirow{2}{*}{\multicolumn{1}{c}{ Dessecantes }} & \multicolumn{4}{c}{ Épocas de aplicação } \\
\cline { 2 - 5 } & $\mathbf{0 5 / 0 3}$ & $\mathbf{1 0 / 0 3}$ & $\mathbf{1 5 / 0 3}$ & $\mathbf{2 0 / 0 3}$ \\
\hline Paraquat & $48 \mathrm{ABb}$ & $52 \mathrm{ABb}$ & $51 \mathrm{Bb}$ & $86 \mathrm{a}$ \\
Diquat & $62 \mathrm{ABb}$ & $67 \mathrm{Aa} \mathrm{b}$ & $79 \mathrm{Aa} \mathrm{b}$ & $88 \mathrm{a}$ \\
Paraquat+diquat & $39 \mathrm{Bb}$ & $72 \mathrm{Aa}$ & $74 \mathrm{ABa}$ & $70 \mathrm{a}$ \\
Glufosinato de amônio & $67 \mathrm{Aa}$ & $29 \mathrm{Bb}$ & $69 \mathrm{ABa}$ & $70 \mathrm{a}$ \\
\hline
\end{tabular}

DMS: Época dentro de dessecantes $=26$

Dessecante dentro de épocas $=26$

${ }^{1}$ Médias seguidas pela mesma letra, minúscula na linha e maiúscula na coluna, não diferem entre si pelo teste de Tukey, ao nível de $5 \%$ de probabilidade. 
da maturação fisiológica, exibiram acréscimos na taxa de lixiviação de potássio e redução da qualidade fisiológica. Também, Andrews (1982) verificou que a lixiviação de açúcares e a condutividade elétrica foram mínimas, enquanto que a germinação foi máxima para as sementes colhidas próximo da maturação fisiológica.

\section{Teores de proteína e extrato etéreo}

O resultados dos dados na Tabela 5, indicaram que os teores de proteína não foram influenciados pelos dessecantes e suas épocas de aplicação. Entretanto, para o extrato etéreo, houve diferença estatística entre as sementes dessecadas (fatorial) e não dessecadas (testemunha), e para as épocas de aplicação. O fato da aplicação dos dessecantes na primeira época (05/03) ter ocorrido 22 dias antes da colheita (27/03), pode justificar o menor teor de extrato etéreo nessa época,

TABELA 5. Análise de variância e valores médios do teor de proteínas e extrato etéreo em sementes colhidas na safra de verão em função da aplicação de dessecantes em diferentes épocas $^{1}$.

\begin{tabular}{lcc}
\hline Épocas/dessecantes & $\begin{array}{c}\text { Proténa } \\
(\%)\end{array}$ & $\begin{array}{c}\text { Extrato etéreo } \\
(\%)\end{array}$ \\
\hline Fatorial & 34,5 & $19,1 \mathrm{~b}$ \\
Testemunha & 33,8 & $20,0 \mathrm{a}$ \\
\hline $05 / 03$ & 33,9 & $18,4 \mathrm{~b}$ \\
$10 / 03$ & 34,3 & $19,2 \mathrm{a}$ \\
$15 / 03$ & 34,9 & $19,1 \mathrm{a}$ \\
$20 / 03$ & 34,9 & $19,3 \mathrm{a}$ \\
\hline Paraquat & 34,2 & 19,0 \\
Diquat & 34,4 & 18,8 \\
Paraquat+diquat & 34,1 & 19,2 \\
Glufosinato de amônio & 35,4 & 18,9 \\
\hline Teste F & & \\
Fatorial vs Testemunha & $0,82^{\mathrm{ns}}$ & $7,15^{*}$ \\
Épocas (E) & $1,31^{\mathrm{ns}}$ & $5,78^{* *}$ \\
Dessecantes (D) & $2,21^{\mathrm{ns}}$ & $1,14^{\mathrm{ns}}$ \\
E. * D. & $0,70^{\mathrm{ns}}$ & $1,40^{\mathrm{ns}}$ \\
DMS Tukey (5\%) & & \\
Epocas e Dessecantes & 1,5 & 0,7 \\
CV (\%) & 4,7 & 3,9 \\
\hline
\end{tabular}

${ }^{1}$ Médias seguidas da mesma letra não diferem entre si pelo Teste de Tukey ao nível de $5 \%$ de probabilidade. pois, talvez, as sementes ainda se encontravam em intenso acúmulo de matéria seca. Quanto mais tardiamente foram efetuadas as aplicações dos dessecantes, os valores de extrato etéreo aproximaram-se aos valores da testemunha, indicando que, quanto mais a semente permanece no campo durante o seu processo de formação maior será o acúmulo deste componente.

\section{Incidência de patógenos}

As análises de incidência de fungos fitopatogênicos em sementes de soja, colhidas na safra de verão (março/abril) e aos seis meses após a conservação das mesmas (setembro/ outubro) em câmara seca com umidade relativa em torno de $40 \%$ e temperatura variando de 17 a $20^{\circ} \mathrm{C}$ são apresentados na Tabela 6.

Os fungos fitopatogênicos de maior ocorrência foram o Fusarium spp. e Phomopsis spp., nas duas épocas em que as sementes foram submetidas ao teste de sanidade. Houve efeito significativo de épocas de aplicação, produtos dessecantes e interação entre épocas e dessecantes, na porcentagem de sementes de soja infectadas por Fusarium spp. colhidas na safra de verão.

O desdobramento da interação significativa em sementes de soja colhidas na safra de verão na Tabela 7, mostrou que o paraquat quando aplicado na primeira época (05/03), ocasionou maiores índices de infecção de Fusarium spp. (51\%) sendo estatísticamente diferente do diquat (30\%) e glufosinato de amônio (12\%). Na segunda época de aplicação (10/03) somente o paraquat e glufosinato de amônio foram diferentes significativamente, não ocorrendo o mesmo nas aplicações realizadas posteriormente. Magalhães et al. (2002), estudando o uso do paraquat na cultura do milho, encontrou maior porcentagem de infecção de grãos por Fusarium subglutinans, patógeno causador de grãos ardidos nesta cultura.

Também na Tabela 6, verifica-se que o paraquat, independente da época em que foi aplicado, ocasionou nível de infecção de Phomopsis spp., nas sementes armazenadas por seis meses, significativamente menor aos observados nos tratamentos efetuados com diquat, mistura paraquat + diquat e glufosinato de amônio, os quais não diferiram significativamente entre si.

Não houve redução no número de sementes infectadas por Phomopsis spp., após seis meses armazenadas (Tabela 6). Esse resultado contraria os trabalhos desenvolvidos por 
TABELA 6. Incidência (\%) de fungos fitopatogênicos avaliadas após a colheita na safra de verão e armazenamento por seis meses em função da aplicação de dessecantes em diferentes épocas ${ }^{1}$. Dados transformados em Raiz Quadrada (variável+1).

\begin{tabular}{|c|c|c|c|c|c|c|c|c|}
\hline \multirow{2}{*}{$\begin{array}{c}\text { Épocas/ } \\
\text { Dessecantes }\end{array}$} & \multicolumn{2}{|c|}{ Cercospora kikuchi } & \multicolumn{2}{|c|}{ Fusarium spp. } & \multicolumn{2}{|c|}{ Phomopsis spp. } & \multicolumn{2}{|c|}{ Fusarium solani } \\
\hline & $\begin{array}{c}\text { Colheita } \\
\text { verão }\end{array}$ & $\begin{array}{c}\text { Armazenada } \\
\text { seis meses }\end{array}$ & $\begin{array}{c}\text { Colheita } \\
\text { verão }\end{array}$ & $\begin{array}{c}\text { Armazenada } \\
\text { seis meses } \\
\end{array}$ & $\begin{array}{c}\text { Colheita } \\
\text { verão }\end{array}$ & $\begin{array}{c}\text { Armazenada } \\
\text { seis meses } \\
\end{array}$ & $\begin{array}{c}\text { Colheita } \\
\text { verão }\end{array}$ & $\begin{array}{c}\text { Armazenada } \\
\text { seis meses } \\
\end{array}$ \\
\hline Fatorial & 0 & 1,3 & 22,0 & 19,1 & 20,0 & 29,3 & 2,5 & 2,3 \\
\hline Testemunha & 0 & 1,5 & 24,0 & 17,5 & 15,5 & 35,0 & 5,0 & 1,0 \\
\hline 05/03 & 0 & 1,5 & $29,0 \mathrm{a}$ & 22,8 & 21,5 & 26,1 & 4,1 & 3,1 \\
\hline $10 / 03$ & 0 & 0,5 & $20,8 a b$ & 17,5 & 16,6 & 31,9 & 1,0 & 2,4 \\
\hline $15 / 03$ & 0 & 2,0 & $18,5 \mathrm{~b}$ & 14,9 & 23,3 & 27,3 & 1,4 & 1,5 \\
\hline $20 / 03$ & 0 & 1,3 & $20,0 \mathrm{~b}$ & 21,3 & 18,3 & 28,8 & 3,6 & 2,1 \\
\hline Paraquat & 0 & 1,6 & $32,1 \mathrm{a}$ & $24,4 \mathrm{a}$ & 22,8 & $18,1 \mathrm{~b}$ & 3,5 & 2,1 \\
\hline Diquat & 0 & 0,7 & $24,3 a b$ & $23,8 \mathrm{ab}$ & 20,1 & 31,3a & 1,8 & 2,5 \\
\hline Paraquat+diquat & 0 & 1,3 & 18,5 bc & $13,5 \mathrm{~b}$ & 16,5 & $32,4 a$ & 2,1 & 1,8 \\
\hline Glufosinato de amônio & 0 & 1,6 & $13,5 \quad \mathrm{c}$ & $14,8 a b$ & 20,3 & $32,4 \mathrm{a}$ & 2,6 & 2,6 \\
\hline \multicolumn{9}{|l|}{ Teste F } \\
\hline Fatorial vs Testemunha & 0 & $0,10^{\mathrm{ns}}$ & $0,28^{\mathrm{ns}}$ & $0,01^{\mathrm{ns}}$ & $0,32^{\mathrm{ns}}$ & $0,88^{\mathrm{ns}}$ & $1,62^{\mathrm{ns}}$ & $0,44^{\mathrm{ns}}$ \\
\hline Épocas (E) & 0 & $0,72^{\mathrm{ns}}$ & $4,70 * *$ & $1,9^{\mathrm{ns}}$ & $0,99^{\mathrm{ns}}$ & $0,57^{\mathrm{ns}}$ & $1,95^{\mathrm{ns}}$ & $0,47^{\mathrm{ns}}$ \\
\hline Dessecantes (D) & 0 & $0,31^{\mathrm{ns}}$ & $13,70 * *$ & $4,2 * *$ & $0,84^{\mathrm{ns}}$ & $4,38 * *$ & $0,41^{\mathrm{ns}}$ & $0,19^{\mathrm{ns}}$ \\
\hline E. *D. & 0 & $0,90^{\mathrm{ns}}$ & $2,20 *$ & $2,0^{\mathrm{ns}}$ & $1,12^{\mathrm{ns}}$ & $1,50^{\mathrm{ns}}$ & $0,84^{\mathrm{ns}}$ & $0,70^{\mathrm{ns}}$ \\
\hline \multicolumn{9}{|l|}{ DMS Tukey (5\%) } \\
\hline Épocas e Dessecantes & 0 & 2,8 & 8,1 & 9,8 & 11,0 & 12,5 & 4,2 & 3,4 \\
\hline CV (\%) & 0 & 36,8 & 21,3 & 31,7 & 29,3 & 23,5 & 42,9 & 40,3 \\
\hline
\end{tabular}

${ }^{1}$ Médias seguidas da mesma letra não diferem entre si pelo Teste de Tukey ao nível de 5\% de probabilidade.

TABELA 7. Desdobramento da interação épocas $x$ dessecantes para o fungo Fusarium spp. em sementes de soja colhidas na safra de verão ${ }^{1}$.

\begin{tabular}{|c|c|c|c|c|}
\hline \multirow{2}{*}{ Dessecantes } & \multicolumn{4}{|c|}{ Épocas de aplicação } \\
\hline & $05 / 03$ & $10 / 03$ & $15 / 03$ & $20 / 03$ \\
\hline Paraquat & $51 \mathrm{Aa}$ & $31 \mathrm{Ab}$ & $23 b$ & $25 b$ \\
\hline Diquat & $30 \mathrm{~B}$ & $23 \mathrm{AB}$ & 20 & 25 \\
\hline Paraquat+diquat & $24 \mathrm{BC}$ & $20 \mathrm{AB}$ & 14 & 16 \\
\hline Glufosinato de amônio & 12 & $10 \mathrm{~B}$ & 18 & 15 \\
\hline
\end{tabular}

DMS:Época dentro de dessecantes $=16$

Dessecante dentro de épocas $=16$

\footnotetext{
${ }^{1}$ Médias seguidas pela mesma letra, minúscula na linha e maiúscula na coluna, não diferem entre si pelo teste de Tukey, ao nível de $5 \%$ de probabilidade.
}

Henning \& Hare (1981), pois os autores concluíram que, após seis meses de armazenamento, o índice de sementes infectadas por Phomopsis spp. diminuiu, aproximadamente para valores iguais a zero e houve aumento na porcentagem de germinação.

A incidência de fungos não fitopatogênicos ou de armazenamento está na Tabela 8. Houve efeito de épocas de aplicação dos dessecantes para o Penicillium spp. As sementes que receberam aplicações de dessecantes obtiveram significativamente maiores indices de Penicillium spp. do que as sementes não dessecadas. A aplicação ocorrida em 10/03 foi diferente, significativamente, das aplicadas em 05/03 e 20/03. As sementes armazenadas apresentaram índices de infecção de Aspergillus spp. e Penicillium spp. menores aos das sementes colhidas em março e abril (safra de verão). A 
TABELA 8. Incidência (\%) de fungos não fitopatogênicos após colheita realizada na safra de verão e armazenadas por seis meses em função da aplicação de dessecantes em diferentes épocas ${ }^{1}$. Dados transformados em Raiz Quadrada (variável+1).

\begin{tabular}{lcccccc}
\hline \multirow{2}{*}{ Épocas/dessecantes } & \multicolumn{2}{c}{ Penicillium spp. } & & \multicolumn{2}{c}{ Aspergillus spp. } \\
\cline { 2 - 3 } \cline { 6 - 7 } & $\begin{array}{c}\text { Colheita } \\
\text { verão }\end{array}$ & $\begin{array}{c}\text { Armazenada } \\
\text { seis meses }\end{array}$ & & $\begin{array}{c}\text { Colheita } \\
\text { verão }\end{array}$ & $\begin{array}{c}\text { Armazenada } \\
\text { seis meses }\end{array}$ \\
\hline Fatorial & 15,9 & $7,9 \mathrm{a}$ & & 0,8 & 0 \\
Testemunha & 8,5 & 2,0 b & & 0,0 & 0 \\
\hline $05 / 03$ & 13,6 bc & 7,8 & & 1,1 & 0 \\
$10 / 03$ & 26,4 a & 9,3 & & 1,3 & 0 \\
$15 / 03$ & 17,5 ab & 12,5 & & 0,5 & 0 \\
$20 / 03$ & 5,8 & c & 5,3 & & 0,3 & 0 \\
\hline Paraquat & 17,1 & 9,9 & & 1,5 & 0 \\
Diquat & 20,6 & 10,1 & & 1,3 & 0 \\
Paraquat+diquat & 14,8 & 8,8 & & 0,1 & 0 \\
Glufosinato de amônio & 10,8 & 5,8 & & 0,4 & 0 \\
\hline
\end{tabular}

Teste F

Fatorial vs Testemunha

Épocas (E)

Dessecantes (D)

$1,69^{\mathrm{ns}}$

$4,15 *$

$0,99^{\mathrm{ns}}$

$8,40 * *$

$2,40^{\text {ns }}$

$1,48^{\mathrm{ns}}$

E. * D.

$1,97^{\mathrm{ns}}$

$1,06^{\text {ns }}$

$2,70^{\mathrm{ns}}$

DMS Tukey (5\%)

Épocas e Dessecantes

$0,58^{\text {ns }}$

$0,64^{\mathrm{ns}}$

$0,91^{\mathrm{ns}}$

CV (\%)

$$
11,0
$$

7,3

1,5

$36,8 \quad 24,5$

${ }^{1}$ Médias seguidas da mesma letra não diferem entre si pelo Teste de Tukey ao nível de 5\% de probabilidade.

maior freqüência de Penicillium spp., nas duas épocas de avaliação de sanidade das sementes, justifica porque as sementes não obtiveram porcentagem de germinação suficiente para comercialização, conforme os resultados mostrado na Tabela 1, pois, segundo Henning (1984) e Goulart (1997) esse fungo geralmente ocorre em sementes de baixa qualidade.

\section{CONCLUSÕES}

Após a colheita da soja na safra de verão e estas armazenadas por seis meses, conclui-se que:

As sementes não apresentaram qualidades fisiológicas suficientes para comercialização, sendo o dessecante glufosinato de amônio que apresentou, estatisticamente, menores valores de germinação.

O teor de proteína não foi influenciado pelas aplicações de dessecantes nas diferentes épocas, entretanto, quanto ao
0

0

0

0

extrato etéreo houve diferença significativa entre as sementes de soja dessecadas e as não dessecadas, sendo que, quanto mais tarde foi realizada a aplicação mais próximo o valor de extrato etéreo em relação à testemunha.

O produto paraquat, aplicado nas primeiras épocas, resultou maior incidência de Fusarium spp., enquanto que, para o Phomopsis spp. menor incidência independente das épocas de aplicações.

\section{REFERÊNCIAS}

ASSOCIATION OF OFFICIAL SEED ANALYSIS. Seed vigor testing handbook. Zürich: AOSA, 1983. 93p.

ANDREWS, C.H. Pre-harvest environment: weathering. In: SINCLAIR, J.B., JACKOBS, J.A., (Eds.) Soybeans seed quality and stand establishment. Urbana: University of Illinois, 1982, p.19-25.

BRASIL, Ministério da Agricultura. Regras para análise de sementes. Brasília: SNDA / CLAV, 1992. 365p.

DURIGAN, J.F.; SÁNCHES, A.L.; ASSIS, G.M. Respostas de genótipos de soja (Glycine max (L.) Merrill) ao retardamento de colheita quanto aos conteúdos de proteína e óleo da semente. Científica, v.17, n.1, p.121-125,1989.

EMBRAPA. Centro de Pesquisa Agropecuária do Oeste. Recomendações técnicas para cultura da soja na região central do Brasil. 1996. Dourados, 1996. 148p.

FEHR, W.R.; CAVINESS, C.E.; BURMOOD, D.T.; PENNINGTON, J.S. Stage of development descriptons for soybeans, Glycine max (L.) Merrill. Crop Science, v.11, p.929-31, 1971.

GOMES, J.L.L. Efeito da aplicação de gramoxone e do reglone sobre a incidência de patógenos nas sementes de soja. In: CONGRESSO BRASILEIRO DE FITOPATOLOGIA, 15, Resumos... São Paulo: Sociedade Brasileira de Fitopatologia, 1982.

GOULART, A.C.P. Principais fungos encontrados em sementes de soja. In: Fungos em sementes: detecção e importância. EMBRAPA: Dourados, 58p., 1997. (Documento, 11).

HENNING, A.A. Qualidade sanitária da semente. In: Qualidade fisiológica e sanitária de sementes de soja. Londrina: EMBRAPA-CNPSo, 1984. p.25-39 (EMBRAPA- CNPSo. Circular Técnica, 9).

HENNING, A.A. Testes de sanidade de sementes de soja. In: SOAVE, J.; WETZEL, M.M.V.S. (eds.) Patologia de Sementes. Campinas: Fundação Cargill, 1987. p.451-453. 
HENNING, A.A.; HARE, W. Efeitos de época de tratamento químico e/ou período de armazenamento sobre a qualidade fisiológica e sanitária das sementes de soja, cv. Bossier e Paraná com altos índices de Phomopsis sp. In: CONGRESSO BRASILEIRO DE SEMENTES, 2, Recife, 1981. Resumos... Brasília: ABRATES, p.24, 1981.

HEYDECKER, W. Vigour. In: ROBERTS, G.H. (ed.) Viability of Seeds. London: Chapman and Hall, 1974. p.209-52.

LACERDA, A.L.S.; LAZARINI, E.; SÁ, M.E; VALTER FILHO, V.V. Aplicação de dessecantes na cultura de soja: antecipação da colheita e produção de sementes. Planta Daninha. v.19, n.3, p. 381390, 2001.

MAGALHÃES, P.C.; DURÃES, F.O.M.; KARAM, D. Eficiência dos dessecantes paraquat e diquat na antecipação da colheita do milho. Planta Daninha, v.20, n.3, p.449-455, 2002.

MALAVOLTA, E.; VITTI, G.C.; OLIVEIRA, S.A. Metodologia para análise de elementos em material vegetal. In :_. Avaliação do estado nutricional das plantas: princípios e aplicações. Piracicaba: Potafós, 1989. p.135 - 189.

MARCOS FILHO, J; AMORIM, H.V.; SILVAROLLA, MB.; PESCARIM, H.M.C. Relações entre germinação, vigor e permeabilidade das membranas celulares durante a maturação de sementes de soja. In: SEMINÁRIO NACIONAL DE PESQUISA DE SOJA, 2, 1981, Brasília, 16 / 21 fev: Anais... Londrina: EMBRAPA - CNPSo, 1982. v.2, p.256.
MARCOS FILHO, J.; CÍCERO, S.M.; SILVA, W.R. Avaliação da qualidade das sementes. Piracicaba: FEALQ, 1987, 230p.

MATTHEWS, S. Evaluation of techniques for germination and vigour studies. Seed Science and Technology, v.9, n.2, p.543-551, 1981.

ROBERTS, E.H. Predicting the storage life of seeds. Seed Science and Technology, v.1, n.3, p.499-514, 1973.

SILVA, D.J. Determinação da gordura bruta ou extrato etéreo. In . Análise de alimentos: métodos químicos e biológicos. Viçosa: UFV, 1981. p.12-15.

SILVA CASTRO, C.A. Produção de n-hexanal e aldeídos totais como índices para avaliar a qualidade fisiológica de sementes de soja (Glycine $\max (\mathrm{L}$.$) Merrill). Viçosa: Universidade Federal$ de Viçosa, 1989, 141 p. (Tese Doutorado).

SOARES, L.F. Efeito da utilização de paraquat na fração lipídica da soja. Viçosa: Universidade Federal de Viçosa, 1995. 47p. (Dissertação Mestrado).

WARD, F.H.; POWELL, A.A. Evidence for repair processes in onion seeds during storage at high seed moisture contents. Journal Experimental Botanic, v.34, n.140, p.277-282, 1983.

WILCOX, J.R.; LAVIOLETTE, F.A.; ATHOW, K.L. Deterioration of soybean seed quality associated with delayed harvest. Plant Disease Reporter, v.58, n.2, p.130-133, 1974. 